\title{
Antifungal Activity of Plant Essential Oils Against Botrytis cinerea, Penicillium italicum and Penicillium digitatum
}

\author{
Andrew VITORATOS', Dimitrios BILALIS²*, Anestis KARKANIS ${ }^{3}$, Aspasia EFTHIMIADOU ${ }^{4}$ \\ ${ }^{1}$ Technological Educational Institute of Ionian Islands, Department of Organic Farming and Food Technology, Argostoli, Kephalonia, Greece \\ ${ }^{2}$ Agricultural University of Athens, Laboratory of Crop Production, Iera Odos 75, 11855 \\ Athens, Greece; bilalisdimitrios@yahoo.gr (*correspondingauthor) \\ ${ }^{3}$ University of Thessaly, Department of Agriculture Crop Production and Rural Environment, Fytokou Str, 38446, Nea Ionia, Magnesia, Greece \\ ${ }^{4}$ Open University of Cyprus, P.O. Box 24801, 1304 Nicosia, Cyprus
}

\begin{abstract}
Plant essential oils have the potential to replace the synthetic fungicides in the management of postharvest diseases of fruit and vegetables.The aim of this study was to access the in vitro and in vivo activity of essential oil obtained from oregano (Origanum vulgare L. ssp. hirtum), thyme (Thymus vulgaris L.) and lemon (Citrus limon L.) plants, against some important postharvest pathogens (Botrytis cinerea, Penicillium italicum and $P$. digitatum). In vitro experiments indicated that $P$. italicum did not show any mycelium growth in presence of thyme essential oils at concentration of $0.13 \mu \mathrm{l} / \mathrm{ml}$. Moreover, $B$. cinerea did not show any mycelium growth in presence of lemon and oregano essential oils at concentration of $17 \mu \mathrm{l} / \mathrm{ml}$ and $0.02 \mu \mathrm{l} / \mathrm{ml}$, respectively. Moreover, the essential oils from three species were effective in reducing the spore germination. The in vivo experiments confirmed the strong efficacy shown in vitro by essential oils. These oregano and lemon oils were very effective in controlling disease severity of infected fruit by $B$. cinera in tomatoes, strawberries and cucumbers. In tomatoes, grey mould due to $B$. cinerea was completed inhibited by oregano essential oils at $0.30 \mu \mathrm{l} / \mathrm{ml}$. Moreover, lemon essential oils induced a significant reduction of grey mould disease severity. In strawberries, grey mould was completed inhibited by lemon essential oils at $0.05 \mu \mathrm{l} / \mathrm{ml}$. In addition, lemon essential oils at $0.05 \mu \mathrm{l} / \mathrm{ml}$ showed $39 \%$ reduction of infected cucumber fruits by B. cinerea. These results indicate that essential oils after suitable formulation could be used for the control of postharvest diseases caused by Botrytis and Penicillium pathogens.
\end{abstract}

Keywords: antifungal activity, postharvest diseases, spore germination, vegetables

\section{Introduction}

Fungal infections are the main cause of postharvest rots of fresh fruit and vegetables during storage, transport and cause significant economic losses in the commercialization phase (Gatto et al., 2011). Infections caused during postharvest conditions lowers the shelf life and adversely affect the market value of fruits (Tripathy et al., 2008). Moreover, mycotoxins the secondary metabolites produced by molds have adverse effects on humans and animals (Zain, 2011). The contamination of fruits with mycotoxins has not only caused health hazards but also resulted in economic losses, especially for exporting countries (Fernandez-Cruz et al., 2010).

Grey mould, blue mould and green mould caused by Botrytis cinerea, Penicillium italicum, Penicillium digitatum, respectively, are common postharvest diseases of fruits and vegetables (Gatto et al., 2011; Solaimani et al., 2009; Tripathi et al., 2008). Chemical fungicides provide the primary means for controlling postharvest fungal decay of fruit and vegetables. Continuous use of fungicides has faced two major obstacles; increasing public concern regarding contamination of fruits and vegetables with fungicidal residues, and proliferation of resistance in the pathogen populations (Tripathi and Dubey, 2004).

Food safety is one of the major issues related to fresh fruit and vegetables (Antunes and Cavaco, 2010). The development of natural crop protective products as alternatives to synthetic fungicides is currently in the spotlight (Combrinck et al., 2011). The natural and bio-control fungicides might be a good alternative to the use of synthetic fungicides, and in turn to fulfil consumer requirements for more natural and healthy foods (Gachango et al., 2012; Martinez-Romero et al., 2008). The use of plant extracts could be a useful alternative to synthetic fungicides in the management of rot fungi during postharvest handling of fruit and vegetables (Gatto et al., 2011).

A new approach to the control of postharvest pathogens, while maintaining fruit quality, has been implemented by the application of essential oils. This approach eliminates the need for synthetic fungicides, thereby complying with consumer preferences, organic requirements and 
reducing environmental pollution (du Plooy et al., 2009). Moreover, Camele et al. (2010) reported that the essential oil of Thymus vulgaris controlled fruit rot by Botrytis cinerea, Phytophthora citrophthora, and Rhizopus stolonifer, but was ineffective against Penicillium italicum. Moreover, essential oils of Verbena officinalis and Origanum vulgare inhibited infection by the first two fungi and only by $P$. citrophthora, respectively. The objective of the present study was to evaluate the in vitro activity of plant essential oils against postharvest fungal pathogens. The antifungal activity of essential oils was also tested on artificially inoculated fruit and vegetables.

\section{Materials and methods}

\section{Fungal pathogens}

The fungi used throughout the present study were Botrytis cinerea, the causal agent of grey mould, Penicillium italicum, causing blue mould of citrus fruit and Penicillium digitatum, causing green mould of citrus fruit. They were provided by the laboratory of the Agricultural University of Athens and cultured on potato dextrose agar (PDA) at $22^{\circ} \mathrm{C}$ (Botrytis cinerea) and $25^{\circ} \mathrm{C}$ (Penicillium italicum, Penicillium digitatum).

\section{Natural products-essential oils}

Oregano (Origanum vulgare L.), thyme (Thymus vulgaris L.) and lemon (Citrus limon L.) oils were used in vitro and in vivo experiments at different rates. They were a kindly offer by "Bioryl" S.A and stored at $4^{\circ} \mathrm{C}$. Appropriate dilutions were in ethanol on the day of use.

\section{Evaluation of antifungal activity of plant essential oils in} vitro

To determine the inhibitory effects of essential oils, selected concentrations of the essential oils were incor- porated into the PDA and poured into petri dishes. Agar discs $(0.3 \mathrm{~cm}$ in diameter) covered with germinated fungal conidia, served as a source of inoculums. These agar discs were placed in the center of petri dishes containing PDA with the corresponding essential oil at different concentrations. Petri dishes were sealed with parafilm to prevent the leak of test oils. The plates without the essential oils were used as control. The plates were incubated for 5-7 days (AlReza et al., 2010). The mycelium growth was measured.

For spore germination assays, spore suspensions of each fungus $\left(10^{3}\right.$ conidia/ $\mathrm{ml}$ counted with a hemocytometer) were prepared in sterile water. $0.1 \mathrm{ml}$ of each suspension was added to Petri dishes containing PDA with and without the test essential oil. The germinated spores were counted after $24 \mathrm{hr}$ of incubation at $22^{\circ} \mathrm{C}$ (B. cinerea) or at $25^{\circ} \mathrm{C}$ (P. italicum and $P$. digitatum) and percentage of spore germination was calculated. Three replicates were used for each concentration of essential oils. The experiment was repeated twice.

\section{Evaluation of antifungal activity of plant essential oils in vivo}

Tomatoes, strawberries and cucumbers were used in vivo experiments. All the fruits were disinfected (LopezReyes et al., 2010) in with sodium hypochlorite solution (2.5\%) for $2 \mathrm{~min}$. After abundant washing with distilled water $(\times 3)$ the fruits were placed in sterile commercial packages.

Strawberry and tomato fruits were used. These fruits were obtained from commercial market. A number of 25 tomato and 30 strawberry fruits were randomly distributed into five replicates. Fruits were arranged by groups in plastic package having three layers of moistened blotters at the bottom. Conidia of $B$. cinerea were recovered from 2-week old cultures by adding $10 \mathrm{ml}$ of sterile water to each plate. The conidia suspension was filtered through

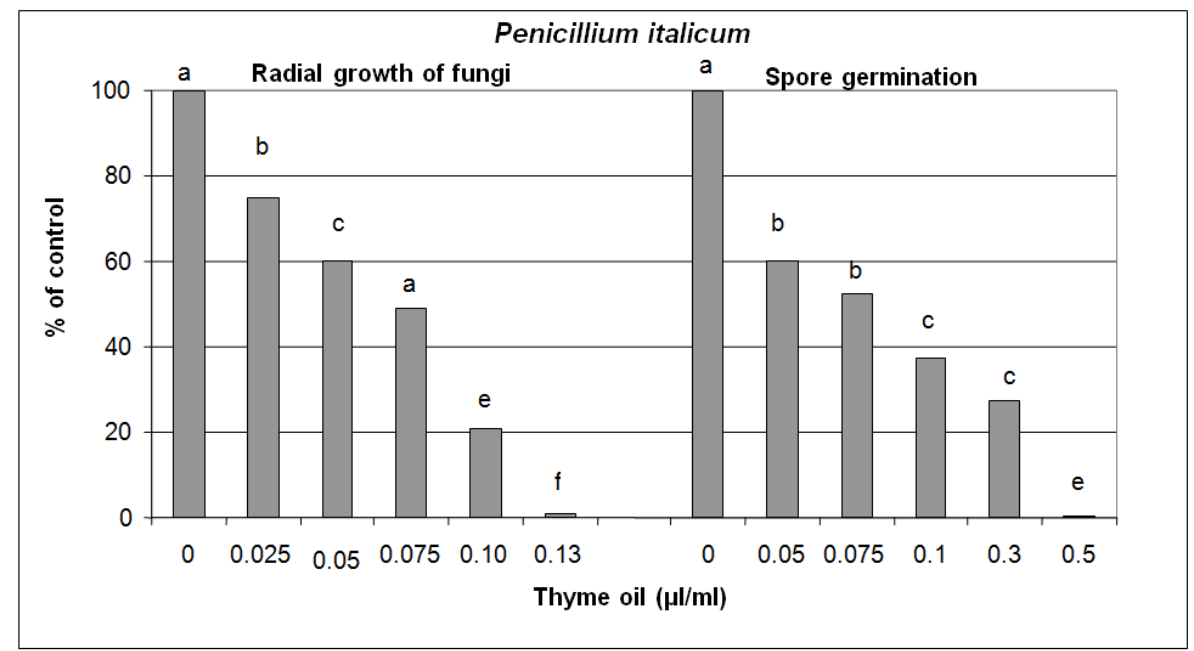

Fig. 1. Effects of thyme oil on radial growth and spore germination of Penicillium italicum. Treatments followed by the same letters are not significant different according to LSD test at $p=0.05$ 
88

three layers of sterile cheesecloth. The concentration of the conidial suspension was adjusted to $10^{5}$ conidia per $\mathrm{ml}$ and a drop of Tween 80 was added to the suspension. Each fruit was inoculated and stored at $22^{\circ} \mathrm{C}$.

Cucumbers were wounded $(1.2 \mathrm{~cm}$ deep and $1.5 \mathrm{~cm}$ diameter-three wounds per fruit) with a cork borer. The wounds were inoculated with spore suspension (LopezReyes et al., 2010) containing $10^{5} \mathrm{spores} / \mathrm{ml}$ of B. cinerea. Thereafter, different concentrations of essential oils were placed in small glass containers placed in the bottom of the package. The fruits were held at $22^{\circ} \mathrm{C}$. A number of 30 fruits were randomly distributed into five replicates. The experiments were repeated twice. The results of two experiments were averaged.

\section{Statistical analysis}

For calculating of analysis of variance and comparisons of means, Statistica software (StatSoft Inc., Tulsa, OK, USA) was used. The LSD test was used to compare the means. Data expressed as percentages were transformed into arcsin square root values to normalize distributions before analysis of variance; the percentages are shown as untransformed data.

\section{Results and discussion}

Inbibitory effects of plant essential oils on in vitro radial growth of pathogens

The in vitro activity of the tested essential oils against the three postharvest pathogens is summarised in Fig. 1-3. The inhibitory effects of plant essential oils were tested at different concentrations.

Essential oils from thyme plants showed a significant activity against Penicillium italicum and $P$. digitatum. In particular, $P$. italicum did not show any mycelium growth in presence of thyme essential oils at concentration of 0.13 $\mu \mathrm{l} / \mathrm{ml}$ (Fig. 1.). Azizi et al. (2008) observed that radial growth of $P$. italicum was completely inhibited by thyme (500 mg/L), Saturega hortensis and Thrachryspermum copticum $(1000 \mathrm{mg} / \mathrm{L})$. Moreover, Abdolahi et al. (2010) reported that thyme essential oils exhibited strong antifungal activity against Botrytis cinerea and Mucor piriformis. According to Šegvić Klarić et al. (2007) the thyme essential oil, which contains p-cymene (36.5\%), thymol (33.0\%) and 1,8-cineole (11.3\%) as main components, and pure thymol exhibited antifungal activities. Pure thymol exhibited approximately three-times stronger inhibition than essential oil of thyme.

Oregano and lemon essential oils showed a significant activity against $B$. cinerea (Fig. 2 . and 3.). The MIC (minimum inhibitory concentrations) value was lowest at oregano treatment (Tab. 1). In particular, B. cinerea did not show any mycelium growth in presence of lemon and oregano essential oils at concentration of $17 \mu \mathrm{l} / \mathrm{ml}$ and $0.02 \mu \mathrm{l} / \mathrm{ml}$, respectively. The $\mathrm{ED}_{50}$ values (Tab. 1 ), the concentration causing $50 \%$ inhibition of radial growth of mycelium, was lowest at oregano treatment followed by thyme treatment.

The most active oils were found to be those of thyme and oregano, while the activity of lemon oil was less effective. According to Fisher and Phillips (2006), essential oils of lemon (Citrus limon), sweet orange (Citrus sinensis) and bergamot (Citrus bergamia) and their components could be used against a number of common foodborne pathogens. The Citrus essential oils consist mainly in monoterpene hydrocarbons (97.59-99.3\%), with limonene (92.52-97.3\%) and $\beta$-pinene (1.37-1.82) being the major constituents (Hosni et al., 2010). Di Vaio et al. (2010) reported that the main component in the lemon essential oil was limonene, accounting for $72.5-76.4 \%$, followed

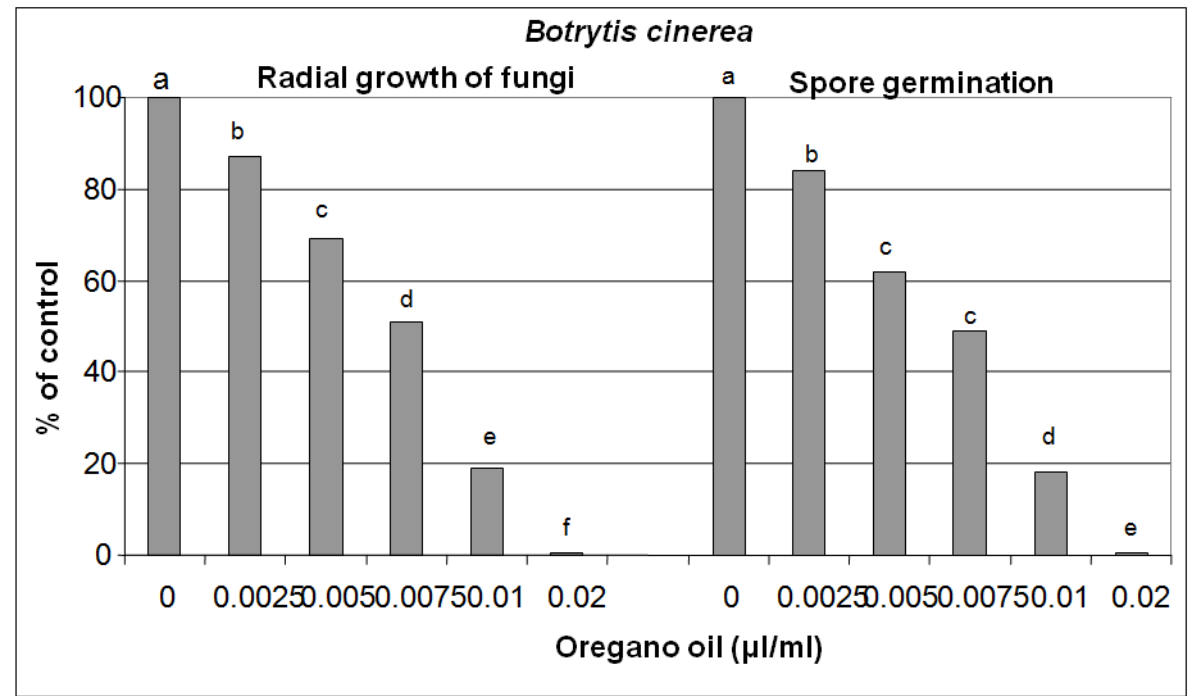

Fig. 2. Effects of oregano oil on radial growth and spore germination of Botrytis cinerea. Treatments followed by the same letters are not significant different according to LSD test at $p=0.05$ 
Tab. 1. Minimum inhibitory concentrations (MIC) and $\mathrm{ED}_{50}$ values (the concentration causing $50 \%$ inhibition) of the plant essential oils against mycelium growth of postharvest pathogens (Botrytis cinerea, Penicillium italicum and P. digitatum)

\begin{tabular}{|c|c|c|c|c|c|c|}
\hline \multirow[b]{2}{*}{ Plant } & \multicolumn{2}{|c|}{ Botrytis cinerea } & \multicolumn{2}{|c|}{ Penicillium italicum } & \multicolumn{2}{|c|}{ Penicillium digitatum } \\
\hline & ED50 & MIC & ED50 & MIC & ED50 & MIC \\
\hline Essential Oils & \multicolumn{2}{|c|}{$(\mu \mathrm{l} / \mathrm{ml})$} & \multicolumn{2}{|c|}{$(\mu \mathrm{l} / \mathrm{ml})$} & \multicolumn{2}{|c|}{$(\mu \mathrm{l} / \mathrm{ml})$} \\
\hline Thyme & - & - & 0.075 & 0.13 & 0.075 & 0.13 \\
\hline Oregano & 0.0075 & 0.02 & - & - & - & - \\
\hline Lemon & 11 & 17 & - & - & - & - \\
\hline
\end{tabular}

Tab. 2. Minimum inhibitory concentrations (MIC) and ED50 values of the plant essential oils against spore germination of postharvest pathogens (Botrytis cinerea, Penicillium italicum and P. digitatum)

\begin{tabular}{|c|c|c|c|c|c|c|}
\hline \multirow[b]{2}{*}{ Plant } & \multicolumn{2}{|c|}{ Botrytis cinerea } & \multicolumn{2}{|c|}{ Penicillium italicum } & \multicolumn{2}{|c|}{ Penicillium digitatum } \\
\hline & ED50 & $\mathrm{MIC}$ & ED50 & MIC & ED50 & MIC \\
\hline Essential Oils & \multicolumn{2}{|c|}{$(\mu \mathrm{l} / \mathrm{ml})$} & \multicolumn{2}{|c|}{$(\mu \mathrm{l} / \mathrm{ml})$} & \multicolumn{2}{|c|}{$(\mu \mathrm{l} / \mathrm{ml})$} \\
\hline Thyme & - & - & 0.075 & 0.50 & 0.075 & 0.50 \\
\hline Oregano & 0.0075 & 0.02 & - & - & - & - \\
\hline Lemon & 13 & 22 & - & - & - & - \\
\hline
\end{tabular}

by $\beta$-pinene (11.6-18.7\%). Moreover, Marei et al. (2012) reported that three monoterpenes (thymol, $(\mathrm{S})$-limonene and 1,8-cineole) are potent antifungal compounds. Citrus oils are generally recognised as safe (GRAS) and have been found to be inhibitory both in direct oil and vapour form against a range of both Gram-positive and Gram-negative bacteria (Fisher and Phillips, 2008). Moreover, Chuah et al. (2010) reported that essential oils from lemon (Citrus limon) exhibited antifungal activity against Fusarium oxysporum and Glomerella cingulata. According to Ozkan et al. (2009) the main components of oregano oil were carvacrol, thymol, $\gamma$-terpinene, $p$-cymene, $\alpha$-terpinene and $\alpha$-pinene. Camele et al. (2012) observed that carvacrol at $250 \mathrm{ppm}$ and thymol at 150 and $250 \mathrm{ppm}$ stopped the growth of $B$. cinerea. Moreover, Soković et al. (2010) re- ported that carvacrol had the highest antibacterial activity among the tested components.

Inhibitory effects of plant essential oils on in vitro spore germination of pathogens

Essential oils from thyme plants showed a significant activity against spore germination of Penicillium italicum and $P$. digitatum. In particular, $P$. italicum did not show any spore germination in presence of thyme essential oils at concentration of $0.5 \mathrm{\mu l} / \mathrm{ml}$ (Fig. 1.). Moreover, oregano and lemon essential oils showed a significant activity against spore germination of Botrytis cinera (Fig. 2. and 3).

According to Liu et al. (2009) thyme oil may provide an alternative means of controlling postharvest sour rot (Geotrichum citri-aurantii) on citrus fruit. At $600 \mu \mathrm{l} / \mathrm{L}$,

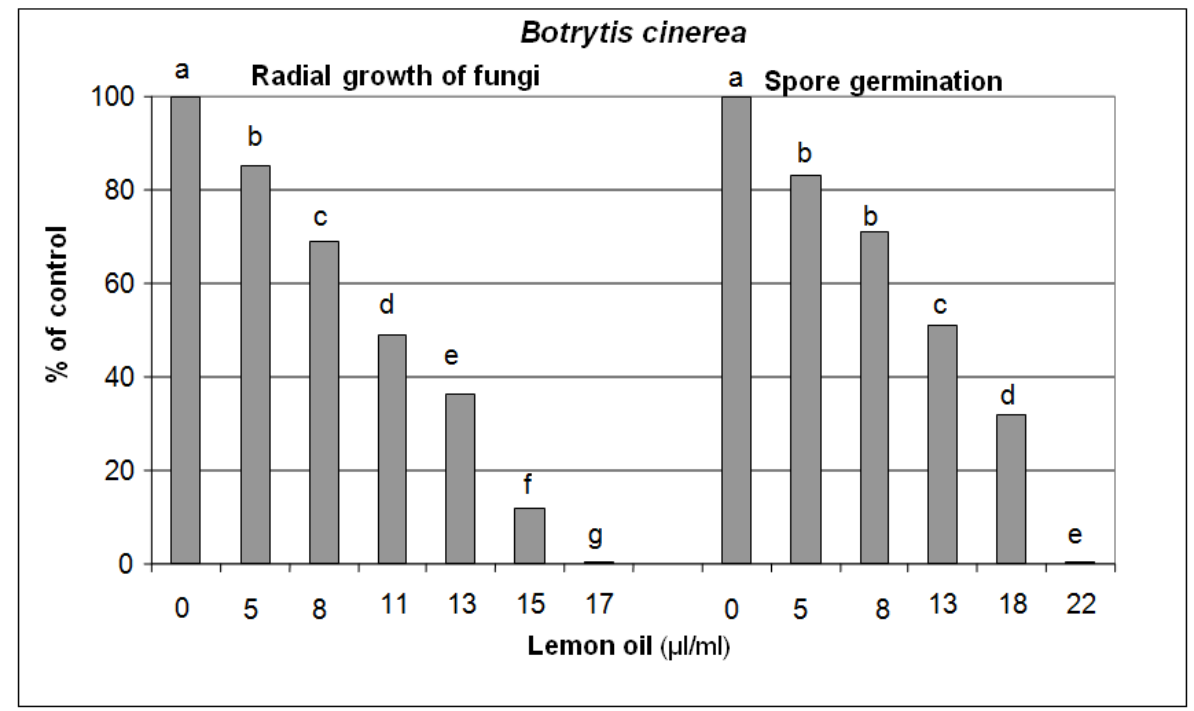

Fig. 3. Effects of lemon oil on radial growth and spore germination of Botrytis cinerea. Treatments followed by the same letters are not significant different according to LSD test at $p=0.05$ 
90

Tab. 3. Activity of oregano and lemon essential oils in reducing the development of Botrytis cinerea on tomatoes, strawberries and cucumbers

\begin{tabular}{cccccc}
\hline \multicolumn{2}{c}{ Tomatoes } & \multicolumn{2}{c}{ Strawberries } & \multicolumn{2}{c}{ Cucumbers } \\
\hline $\begin{array}{c}\text { Oregano oils } \\
(\mu \mathrm{l} / \mathrm{ml})\end{array}$ & $\begin{array}{c}\text { Infected fruits } \\
\%\end{array}$ & $\begin{array}{c}\text { Lemon oils } \\
(\mu \mathrm{l} / \mathrm{ml})\end{array}$ & $\begin{array}{c}\text { Infected fruits } \\
\%\end{array}$ & $\begin{array}{c}\text { Lemon oils } \\
(\mu \mathrm{l} / \mathrm{ml})\end{array}$ & $\begin{array}{c}\text { Infected fruits } \\
\%\end{array}$ \\
\hline 0 & $100^{\mathrm{a}}$ & 0 & $100^{\mathrm{a}}$ & 0 & $100^{\mathrm{a}}$ \\
0.08 & $62.5^{\mathrm{b}}$ & 0.01 & $75^{\mathrm{b}}$ & 0.01 & $80^{\mathrm{b}}$ \\
0.12 & $45.6^{\mathrm{c}}$ & 0.025 & $32.5^{\mathrm{c}}$ & 0.025 & $54.8^{\mathrm{c}}$ \\
0.22 & $18.7^{\mathrm{d}}$ & 0.035 & $25^{\mathrm{c}}$ & 0.05 & $39.6^{\mathrm{c}}$ \\
0.30 & $0^{\mathrm{c}}$ & 0.05 & $0^{\mathrm{d}}$ & 0.075 & 0.125 \\
\hline
\end{tabular}

In each column, values followed by the same letters are not significant different according to LSD test at $p=0.05$

thyme oil it inhibited the germination of about $94 \%$ of the arthroconidia and the germ tube length was only $4.32 \pm$ $0.28 \mu \mathrm{m}$. Moreover, Šegvić Klarić et al. (2007) reported that the vaporous phase of the thyme essential oil $(82 \mu \mathrm{g}$ $\mathrm{I}^{-1}$ ) in glass chambers strongly suppressed the sporulation of moulds during 60 days of exposure.

Botrytis cinerea did not show spore germination in presence of lemon and oregano essential oils at concentration of $22 \mu \mathrm{l} / \mathrm{ml}$ and $0.02 \mu \mathrm{l} / \mathrm{ml}$, respectively. The $\mathrm{ED}_{50}$ values (Tab. 2), the concentration causing $50 \%$ inhibition of spore germination, was lowest at oregano treatment followed by thyme treatment. The most active oils were found to be those of thyme and oregano, while the activity of lemon oil was less effective.

\section{Evaluation of essential oils antifungal activity in vivo}

The effects of oregano, thyme and lemon essential oils on the fungal growth of Botrytis cinerea in inoculated tomatoes, strawberries and cucumbers (Fig. 4.) were evaluated. The oregano and lemon essential oils were highly effective in reducing the infection caused by $B$. cinerea on tomatoes, strawberries and cucumbers (Tab. 3.)
Moreover, Lopez-Reyes et al. (2010) reported that essential oils from oregano, savory (Saturega montana) and thyme showed significant efficacy against postharvest pathogens B. cinerea and Penicillium expansum. Phillips et al. (2012) observed that citrus essential oils reduced spore germination of pathogens Penicillium chrysogeum, Aspergilus niger and Alternaria alternata.

Plant essential oils showed different activity in inhibiting disease development in tomatoes, strawberries and cucumbers. In tomatoes, grey mould due to $B$. cinerea was completed inhibited by oregano essential oils at $0.30 \mu \mathrm{l} /$ $\mathrm{ml}$. Moreover, lemon essential oils induced a significant reduction of grey mould disease severity. In addition, the thyme essential oils were ineffective in reducing the infection caused by $B$. cinerea. In strawberries, grey mould was completed inhibited by lemon essential oils at $0.05 \mu \mathrm{l} /$ $\mathrm{ml}$. In addition, lemon essential oils at $0.05 \mu \mathrm{l} / \mathrm{ml}$ showed $39 \%$ reduction of infected cucumber fruits by $B$. cinerea. Fungal infection was noticed after 5 days with oregano oil treatment and 6 days with lemon oil treatment, while in the control the infections were evident after $48 \mathrm{~h}$ of storage at $22^{\circ} \mathrm{C}$.
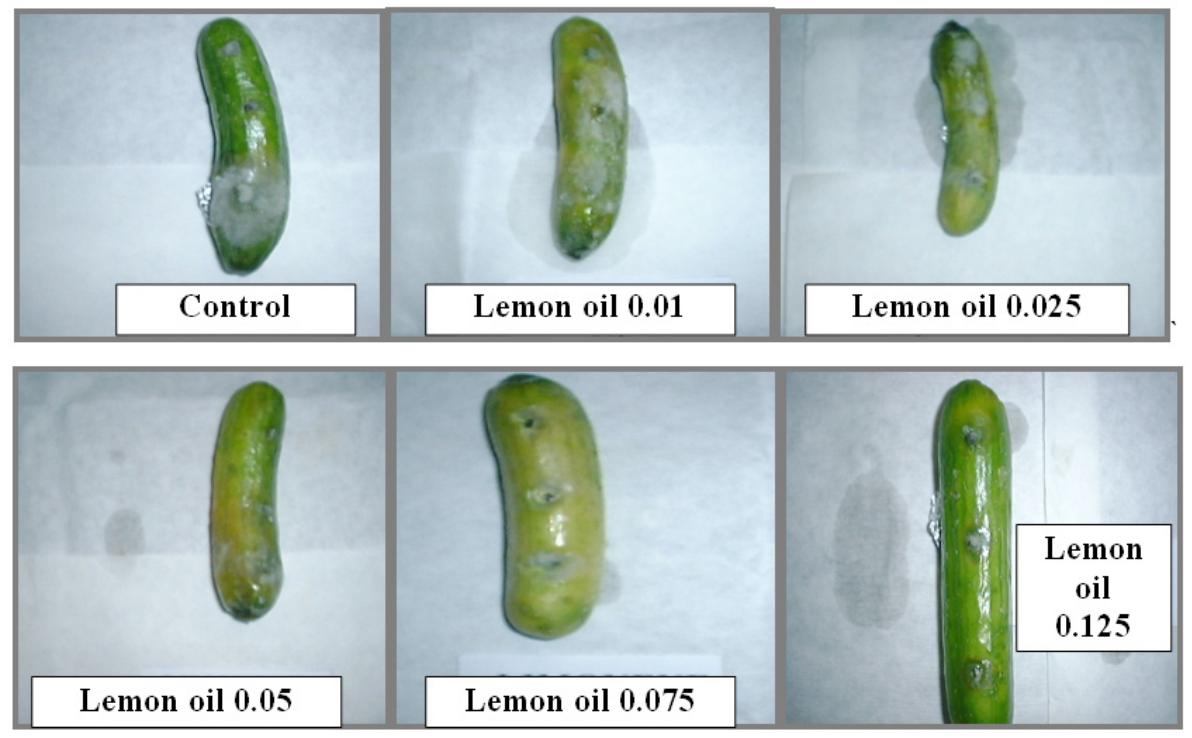

Fig. 4. In vivo antifungal activity of lemon essential oils $(\mu \mathrm{l} / \mathrm{ml})$ against Botrytis cinerea causing grey mould in cucumber 


\section{Conclusions}

The results obtained from both in vitro and in vivo experiments indicated that lemon, thyme and oregano essential oils inhibited the mycelium growth and spore germination of postharvest pathogens (B. cinerea, $P$ italicum, $P$ digitatum). In both experiments, a dose effect was observed, with an increase of antifungal as the essential oils concentration increased. Therefore, essential oils could be used in treatment of fruits and vegetables against postharvest pathogens.

\section{References}

Abdolahi A, Hassani A, Ghuosta Y, Bernousi I, Meshkatalsadat MH (2010). In vitro efficacy of four plant essential oils against Botrytis cinerea Pers. Fr. and Mucor piriformis A. Fischer. J Essent Oil Bear Plant 13:97-107.

Al-Reza SM, Rahman A, Ahmed Y, Kang SC (2010). Inhibition of plant pathogens in vitro and in vivo with essential oil and organic extracts of Cestrum nocturnum L. Pestic Biochem Physiol 96: 86-92.

Antunes MDC, Cavaco AM (2010). The use of essential oils for postharvest decay control. A review. Flavour Fragr J 25:351366.

Azizi M, Farzad S, Jafarpour B., Rastegar MF, Jahanbankhsh V (2008). Inhibitory effect of some medicinal plants essential oils on post harvest fungal disease of citrus fruits. Acta Hortic 768:279-286.

Camele I, Altieri L, De Martino L, De Feo V, Mancini E, Rana GL (2012). In vitro control of post-harvest fruit rot fungi by some plant essential oils components. Int J Mol Sci 13:22902300.

Camele I, De Feo V, Altieri L, Mancini E, De Martino L, Luiqi Rana $G$ (2010). An attempt of postharvest orange fruit rot control using essential oils from Mediterranean plants. J Med Food 13:1515-1523.

Chuah TS, Tan YY, Ismail BS (2010). In vitro evaluation of the antifungal activity of some essential oils on postharvest fungal pathogens of tropical fruits. Plant Prot Q 25:162-164.

Combrinck S, Regnier T, Kamatou GPP (2011). In vitro activity of eighteen essential oils and some major components against common postharvest fungal pathogens of fruit. Ind Crops Prod 33:344-349.

Di Vaio C, Graziani G, Gaspari A, Scaglione G, Nocerino S, Ritieni A (2010). Essential oils content and antioxidant properties of peel ethanol extract in 18 lemon cultivars. Sci Hortic 126:50-55.

du Plooy W, Regnier T, Combrinck S (2009). Essential oil amended coatings as alternatives to synthetic fungicides in citrus postharvest management. Postharvest Biol Technol 53:117-122.

Fernandez-Cruz ML, Mansilla ML, Tadeo JL (2010). Mycotoxins in fruits and their processed products: Analysis, occur- ance and health implications. J Adv Res 1:113-122.

Fisher K, Phillips C (2008). Potential antimicrobial uses of essential oils in food: Is citrus the answer? Trends Food Sci Technol 19:156-164.

Fisher K, Phillips CA (2006). The effect of lemon, orange and bergamot essential oils and their components on the survival of Campylobacter jejuni, Escherichia coli O157, Listeria monocytogenes, Bacillus cereus and Staphylococcus aureus in vitro and in food systems. J ApplMicrobiol 101:1232-1240.

Gachango E, Kirk W, Schafer R, Wharton P (2012). Evaluation and comparison of biocontrol and conventional fungicides for control of postharvest potato tuber diseases. Biol Control 63:15-120.

Gatto MA, Ippolito A, Linsalata V, Cascarano NA, Nigro F, Vanadia S, Di Venere D (2011). Activity of extracts from wild edible herbs against postharvest fungal diseases of fruit and vegetables. Postharvest Biol Technol 61:72-82.

Hosni K, Zahed N, Chrif R, Abid I, Medfei W, Karell M, Brahim NB, Sebei H (2010). Composition of peel essential oils from four selected Tunisian citrus species: Evidence for the genotypic influence Original Research Article. Food Chem 123:1098-1104.

Liu X, Wang LP, Li YC, Li HY, Yu T, Zheng XD (2009). Antifungal activity of thyme oil against Geotrichum citri-aurantii in vitro and in vivo. J Appl Microbiol 107:1450-1456.

Lopez-Reyes JG, Spadaro D, Gullinoa Ml, Garibaldia A (2010). Efficacy of plant essential oils on postharvest control of rot caused by fungi on four cultivars of apples in vivo. Flavour Fragr J 25:171-177.

Marei G, Rasoul MAA, Abdelgaleil SAM (2012). Comparative antifungal activities and biochemical effects of monoterpenes on plant pathogenic fungi. Pestic Biochem Physiol 103:56-61.

Martinez-Romero D, Serrano M, Bailen G, Guillen F, Zapata PJ, Valverde JM, Castillo S, Fuetes M, Valero D (2008). The use of a natural fungicide as an alternative to preharvest synthetic fungicide treatments to control lettuce deterioration during postharvest storage. Postharvest Biol Technol 47:54-60.

Ozkan G, Baydar H, Erbas S (2010). The influence of harvest time on essential oil composition, phenolic constituents and antioxidant properties of Turkish oregano (Origanum onites L.). J Sci Food Agric 90:205-209.

Phillips CA, Laird K, Allen SC (2012). The use of Citri-V ${ }^{\text {two }}$ An antimicrobial citrus essential oil vapour for the control of Penicillium chrysogenum, Aspergillus niger and Alternaria alternata in vitro and on food. Food Res Int 47:310-314.

Šegvić Klarić M, Kosalec I, Mastelić J, Piecková E, Pepeljnak S (2007). Antifungal activity of thyme (Thymus vulgaris L.) essential oil and thymol against moulds from damp dwellings. Lett Appl Microbiol 44:36-42.

Soković M, Glamočlija J, Marin PD, Brkić D, Griensven LJLD (2010) Antibacterial effects of the essential oils of commonly consumed medicinal herbs Using an in vitro model. Mol 
92

15:7532-7546.

Solaimani B, Ramezani M, Saharkiz MJ (2009). Biological control of postharvest disease caused by Penicillium digitatum and $P$. italicum on stored citrus fruits by Shiraz thyme essential oil. Adv Environ Biol 3:249-254.

Tripathi P, Dubey NK (2004). Exploitation of natural products as an alternative strategy to control postharvest fungal rotting of fruit and vegetables. Postharvest Biol Technol $32: 235-245$.
Tripathi P, Dubey NK, Shukla AK (2008). Use of some essential oils as post-harvest botanical fungicides in the management of grey mould of grapes caused by Botrytis cinerea. World J Microbiol Biotechnol 24:39-46.

Zain ME (2011). Impact of mycotoxins on humans and animals. J Saudi Chem Soc 15:129-144. 